\title{
Transverse Vibration Analysis of the Riser in Deep Water
}

\author{
Zifeng $\mathrm{Li}^{1,{ }^{1,}}$, Peng Wang ${ }^{2}$, Min Zhao ${ }^{1}$ and Xuejiao $\mathrm{Li}^{1}$ \\ ${ }^{I}$ Yanshan University, Qinhuangdao 066004, China; ${ }^{2}$ Daqing Oilfield Production Engineering \& Research Institute, \\ Daqing, 163453, China
}

\begin{abstract}
With high international oil price, the exhaustion of onshore resources and declination of oil and gas production in shallow sea, deep water has become the important succeeding area of worldwide oil and gas. During deepwater oil and gas development, riser must be used to isolate seawater, circulate drilling fluid, and compensate the heaving movements of the string and so on. However, with the operating water depth increasing, the loads of waves and ocean currents on the riser become more complex, leading to extremely high construction risk and funds risk of deep-water operations. In this paper, considering the combined action of inside and outside fluid on the riser, transverse vibration partial differential equation is derived, and solved with finite difference method. Meanwhile, transverse displacement response of the riser acted by outer load is determined, and the shear force, bending moment and bend angle at different locations are solved, then the influence factors of riser transverse vibration are analyzed. The mechanical analysis of marine riser can provide a theoretical guidance for safe and effective drilling work, which is of great significance for the offshore oil and gas development.
\end{abstract}

Keywords: Deep water, finite difference, marine riser, mechanical analysis, mechanical model, transverse vibration.

\section{INTRODUCTION}

With high oil price, the exhaustion of onshore resources and declination of oil and gas production in shallow sea, deep water has become the important succeeding area of worldwide oil and gas. During deep-water oil and gas development, riser must be used to isolate seawater, circulate drilling fluid, and compensate the heaving movements of the string and so on. However, with the operating water depth increasing, the loads of waves and ocean currents on the riser become more complex, leading to extremely high construction risk and funds risk of deep-water operations [1-5]. The mechanical analysis of marine riser can provide a theoretical guidance for safe and effective drilling work, which is of great significance for the offshore oil and gas development.

In relation to vibration analysis of marine risers, energy and finite element methods were used to investigate the effects of internal flow on the dynamic responses of the marine risers [6]. Newark integration and Fourier expansion methods were used to compare the dynamic responses of marine risers to harmonic wave and linear hydrodynamic drag forces [7]. The parametric excitation of vertical elastic slender structures and the damping effect were investigated in marine applications [8]. It has been improved to incorporate the flexible riser motion calculation module and VIV induced fatigue calculation module [9-11]. Although, in their investigation, the external factors have not been taken into account, such as top tension, buoyancy block and period of wave. In this study, the marine risers are modeled as the beam in two dimensional spaces. Finite difference method used to formulate and solve the response of riser dynamics is

\footnotetext{
*Address correspondence to this author at the Yanshan University, Qinhuangdao 066004, China: Tel: +86 13930359622; Fax: 86-335-8079211; E-mail: zfli@ysu.edu.cn
}

a highlight in this paper, meanwhile, sensitivity analysis of the riser transverse vibration has been discussed.

\section{MATHEMATICAL MODEL OF TRANSVERSE VIBRATION OF THE RISER IN DEEP WATER}

In analysis of transverse vibration of riser in deep water, calculation and results are mainly dependent on the mathematical model and environment loads accurately. In fact, the environment loads acted on the riser are of uncertainties related with wind, waves, current, sea water level and so on [12-14]. However, restricted by the conditions of scientific research, the content of this paper is based on the following fundamental assumptions. Mechanical characteristics of deep water riser like that of the tender bar are with the top and the bottom boundary conditions [15].

\subsection{Fundamental Assumptions}

(1) Flow rate of inner fluid of the riser is constant;

(2) Waves and ocean currents are in the same direction;

(3) Cross section of the riser is a uniform ring;

(4) Material of the riser cross section is homogeneous;

(5) The riser deformation is considered as small deflection;

(6) The top boundary and bottom boundary of the riser are hinged.

\subsection{Coordinate System}

Ocean current direction and wave direction are considered in the same plane; therefore, choose the plane Cartesian coordinate system, namely oxz plane (Fig. 1). The origin o is at the wellhead, on sea bed; $z$ is the depth coordinate of the riser from the wellhead upward; $x$ is from the wellhead to right. 


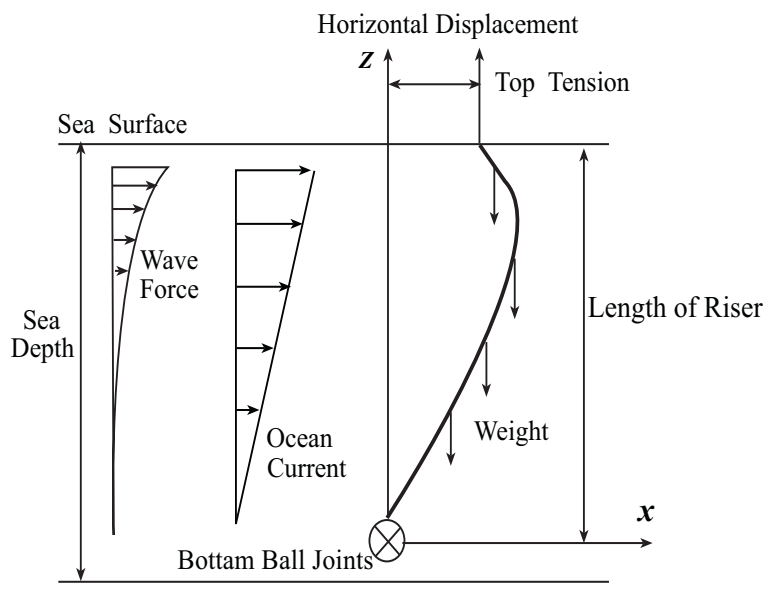

Fig. (1). Mechanical analysis of riser system.

\subsection{Differential Equations}

This paper adopts the differential equations in literature [16]. The combined actions of internal and external of the fluid, and axial force are considered in the equations, ignoring the influence of transverse vibration of internal operation of tubing/drill string in the riser

$$
\left\{\begin{array}{l}
E I \frac{\partial^{4} x}{\partial z^{4}}+\left(m_{\mathrm{d}} v^{2}+p\right) \frac{\partial^{2} x}{\partial z^{2}} \\
+\left(m_{\mathrm{c}}+m_{\mathrm{d}}+\rho_{\mathrm{w}} C_{\mathrm{M}} \frac{\pi D^{2}}{4}\right) \frac{\partial^{2} x}{\partial t^{2}} \\
+2 m_{\mathrm{d}} v \frac{\partial^{2} x}{\partial z \partial t}+\frac{\partial p}{\partial z} \frac{\partial x}{\partial z} \\
+\frac{1}{2} \rho_{\mathrm{w}} \mathrm{C}_{\mathrm{D}} D(u+v)|u+v|=0 \\
v=\frac{\pi H}{T} \frac{\operatorname{ch} k z}{\operatorname{sh} k d} \cos (k x-\omega t)
\end{array}\right.
$$

Where

$$
\begin{aligned}
& E I=\text { flexural rigidity of the riser, } \mathrm{Pa} . \mathrm{m}^{4} \text {; } \\
& x=\text { transverse vibration displacement of the riser, } \mathrm{m} \text {; } \\
& z=\text { depth coordinate of the riser, } \mathrm{m} \text {; wellhead of sea- } \\
& \text { bed is the origin, up is positive; } \\
& v=\text { mean velocity of inner fluid, } \mathrm{m} / \mathrm{s} \text {; } \\
& p \quad=\quad \text { axial force of the riser, } \mathrm{N} \text {; } \\
& m_{\mathrm{d}}=\text { mass of inner fluid per length, } \mathrm{kg} / \mathrm{m} \text {; } \\
& m_{\mathrm{c}}=\text { mass of the riser per length, } \mathrm{kg} / \mathrm{m} \text {; } \\
& \rho_{\mathrm{w}}=\text { density of seawater, } \mathrm{kg} / \mathrm{m}^{3} \text {; } \\
& \mathrm{C}_{\mathrm{M}}=\text { inertia force coefficient, (0.93-2.30); } \\
& D=\text { external diameter of the riser, } \mathrm{m} \text {; } \\
& t=\text { time of the riser vibration, } \mathrm{t} \text {; } \\
& \mathrm{C}_{\mathrm{D}}=\text { drag coefficient, (0.40-1.60); } \\
& u=\text { flow velocity of ocean current, } \mathrm{m} / \mathrm{s} \text {; } \\
& v=\text { flow velocity of wave, } \mathrm{m} / \mathrm{s} \text {; }
\end{aligned}
$$

$H=$ wave height, $\mathrm{m}$;

$T=$ cycle, $\mathrm{s}$;

$d=$ depth of ocean, $\mathrm{m}$;

$k=$ wave number, $k=2 \pi / L$;

$L=$ wavelength, $\mathrm{m}$;

$\omega=$ circular frequency of wave, $\omega=2 \pi / T$.

Ocean current velocity is a linear relation with the sea water depth, the velocity of the waves is calculated according to the Airy wave theory.

$\mathrm{C}_{\mathrm{M}}$ and $\mathrm{C}_{\mathrm{D}}$ are decided by the maximum ocean current speed, the riser radius, and the viscosity of the sea water $[17,18]$.

\subsection{Boundary Conditions}

(1) Top boundary condition

$\left\{\begin{array}{l}x(d, t)=S \\ \left.\frac{\mathrm{d}^{2} x(z, t)}{\mathrm{d} z^{2}}\right|_{z=d}=0\end{array}\right.$

where, $S$ is displacement of riser top.

(2) Bottom boundary condition

$$
\left\{\begin{array}{l}
x(0, t)=0 \\
\left.\frac{\mathrm{d}^{2} x(z, t)}{\mathrm{d} z^{2}}\right|_{z=0}=0
\end{array}\right.
$$

\subsection{Periodic Boundary Condition}

$$
\left\{\begin{array}{l}
x(\mathrm{z}, t)=x(z, t+T) \\
\frac{\partial x(z, t)}{\partial t}=\frac{\partial x(z, t+T)}{\partial t}
\end{array}\right.
$$

\section{EXAMPLES}

The above mathematical model is solved by finite difference method $[19,20]$. In this paper, the example reference to sea state of the South China Sea (SCS). Parameters listed below: the length of the riser is $1000 \mathrm{~m}$; outer diameter is $0.533 \mathrm{~m}$, wall thickness is $0.0254 \mathrm{~m}$, drilling fluid density is $1200 \mathrm{~kg} / \mathrm{m}^{3}$, the depth of water is $1000 \mathrm{~m}$, sea water density is $1030 \mathrm{~kg} / \mathrm{m}^{3}$, the current velocity is $1 \mathrm{~m} / \mathrm{s}$ (assume that current velocity changes linearly with depth of ocean), the waves cycle is $8 \mathrm{~s}$, the waves height is $6.5 \mathrm{~m}$, the riser gets top tension is $1.2 \mathrm{G}$ ( $\mathrm{G}$ is the riser float weight), the riser density is $7850 \mathrm{~kg} / \mathrm{m}^{3}$, the elastic modulus is $2.1 \times 10^{11} \mathrm{~Pa}$, ignoring of auxiliary line, the resistance coefficient of the riser is 1.2 , inertial coefficient is 2.0 .

\subsection{Transverse Displacement of the Riser}

Along with the increase of depth, the transverse displacement response time histories are obtained in Fig. (2). The maximum transverse displacement is in the upper section of the riser, near sea level, which conforms to the actual situation. Below sea level dozens of meters, the riser is 
Transvarse displacement of the riser (m)

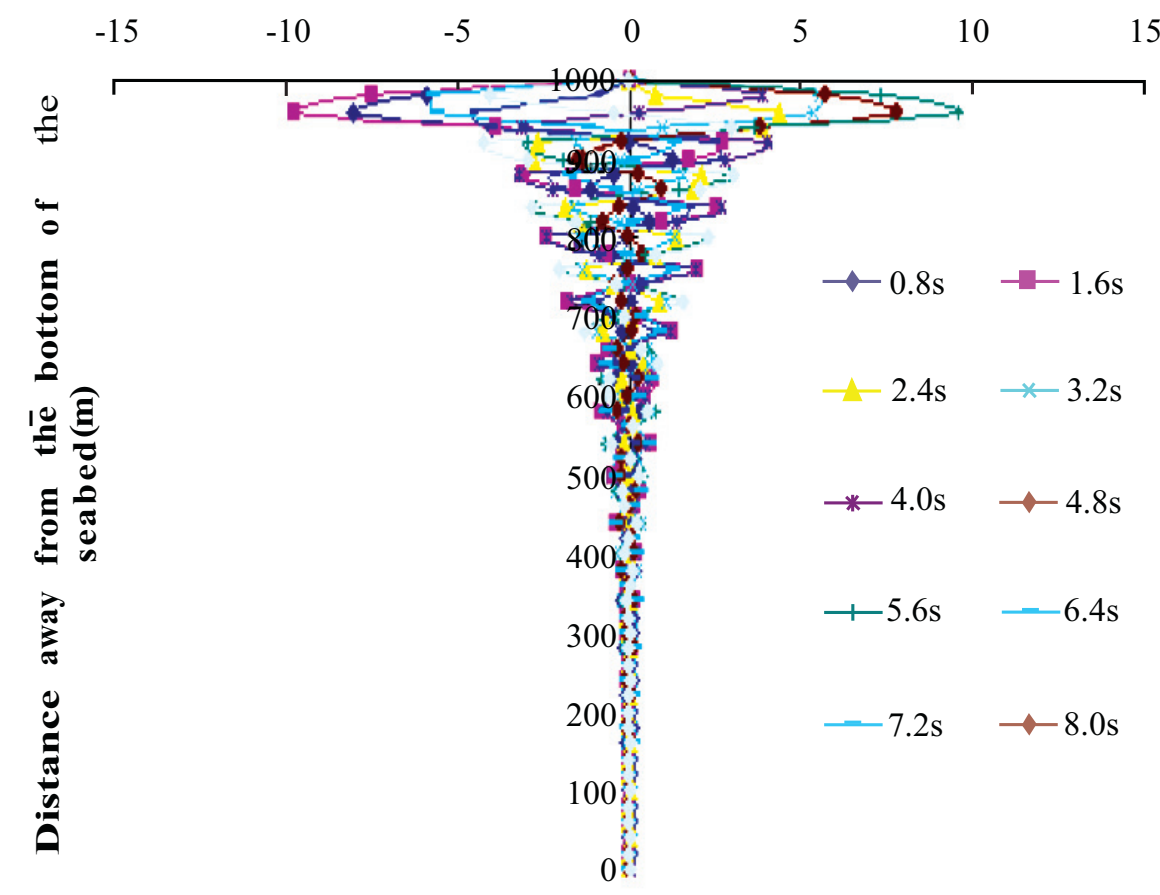

Fig. (2). Transverse displacement of the riser.

damaged easily, because the load of the current and the waves are huge, and the riser is under cyclic loading which also increases the risk of fatigue damage [21].

\subsection{Bend Angle of the Riser}

The bend angle response time histories along with the increase of depth are obtained in Fig. (3). The maximum bend angle is at the top of the riser, it is because the current impacts platform and the riser, which make the riser drifting off center axis. There is an important significance to control the size of the bend angle of the riser, such as reducing the riser damage, reducing the opportunity that the internal pipe wears the riser. Analysis results are in according with literature [22].

\subsection{Bending Moment of the Riser}

The bending moment response time histories along with the increase of depth are obtained in Fig. (4). The bending moment of the riser is larger at the upper section of the riser.

\subsection{Shear Force of the Riser}

The shear force response time histories along with the increase of depth are obtained in Fig. (5). The shear force changes periodically, which can be used to calculate shear stress.

\section{FACTORS AFFECTING TRANSVERSE VIBRA- TION OF THE RISER}

Transverse vibration of the riser is affected by many factors. Firstly, external environment factors include the force of current wave, wave height and sea wind. The top tension and platform drift greatly influence transverse vibration of the marine riser. Besides, the riser material also has certain effects.

\subsection{Top Tension on Transverse Vibration of the Riser}

The transverse vibration is affected by top tension force. If top tension ratio is 1.2 , then the top tension is $3.04 \times 10^{6}$ $\mathrm{N}$. If top tension ratio is 1 , then the top tension is $2.53 \times 10^{6}$ $\mathrm{N}$.

The top tension of riser has obvious influence on the transverse vibration of the riser. Along with the increase of top tension, the riser transverse displacement will be decreased (Fig. 6).

\subsection{Buoyancy on Transverse Vibration of the Riser}

The transverse vibration is affected by the buoyancy force. Increasing the number of buoyancy, the riser effective weight reduces, and it also reduces the top tension. Meanwhile, with the current force increasing acted on the riser, which eventually led to enlarging of the riser transverse displacement (Fig. 7), at the same time, the riser inclination angle, bending moment, and shear force increased. Therefore, it is necessary to consider all factors for optimization design of a riser.

\subsection{The Period of Wave on Transverse Vibration of the Riser}

The transverse vibration is affected by the period of wave. The riser transverse displacement response is calculated for the wave cycles respectively 8 s and 80s (Fig. 8). The results show that, with the increase of the cycle, the riser transverse displacement will be increased and more stable. 


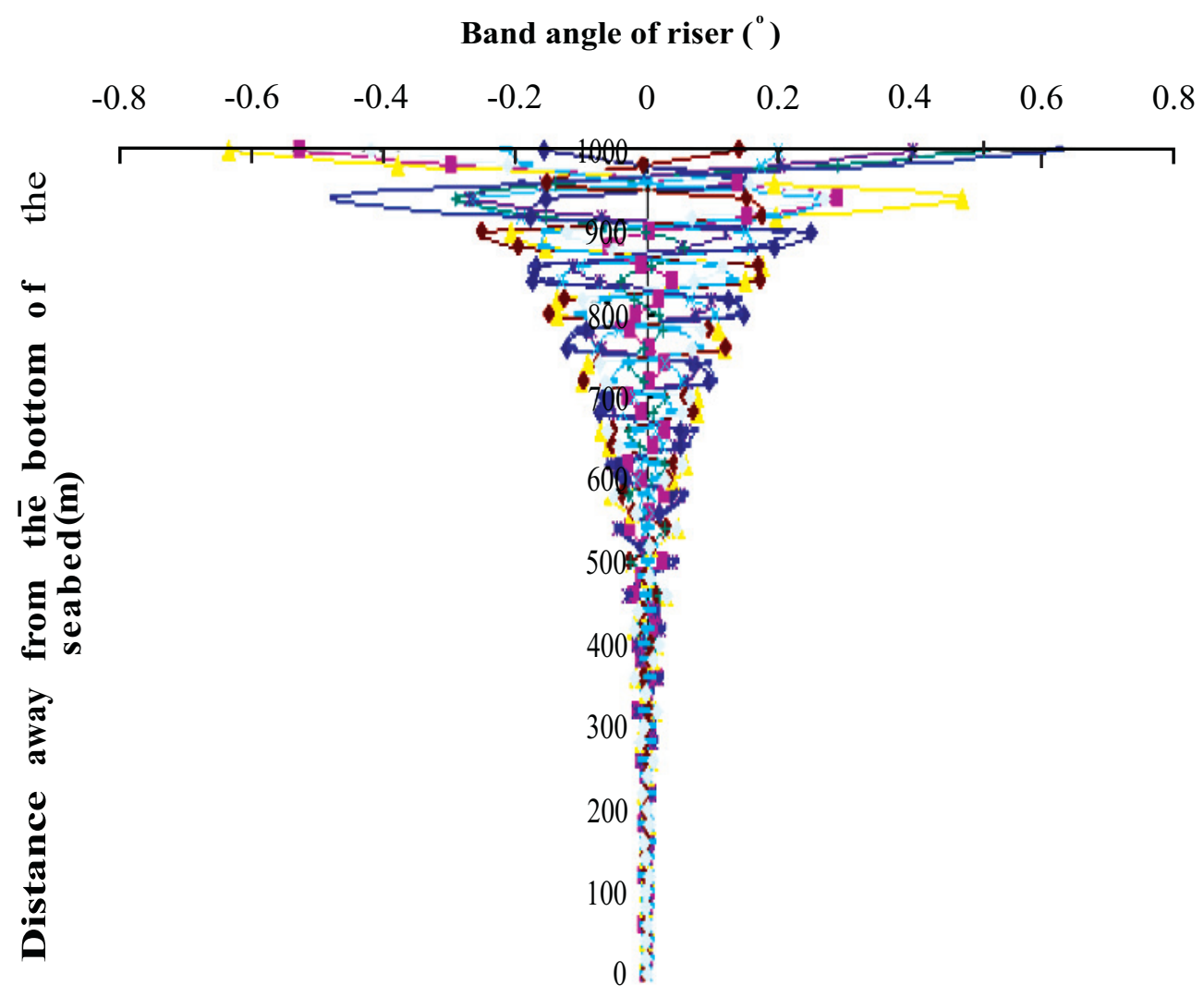

Fig (3). Bend angle of the riser.

Bending moment of the riser $\left(\mathbf{N}^{*} \mathbf{m}\right)$

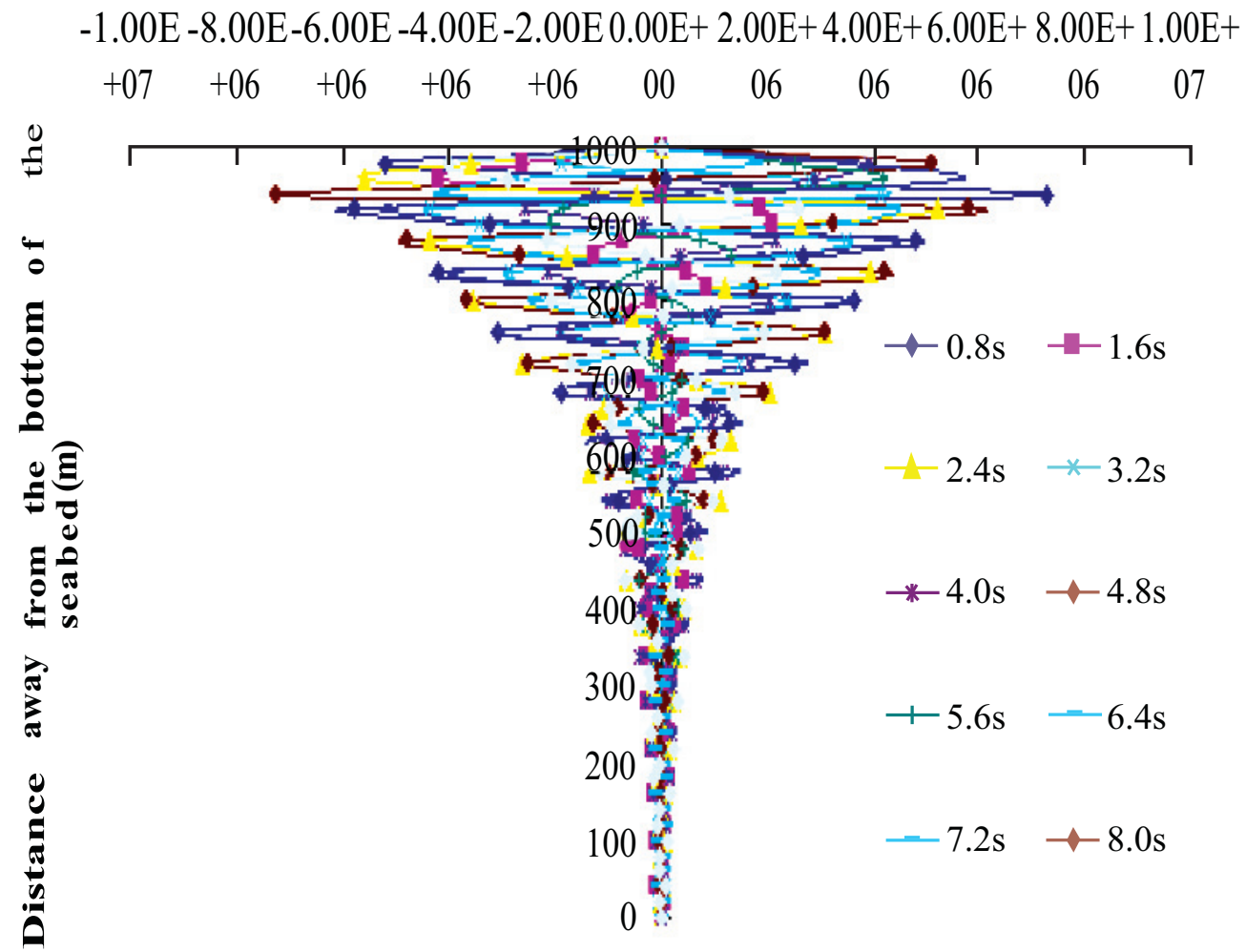

Fig (4). Bending moment of the riser. 
Shear force of the riser $(\mathrm{N})$

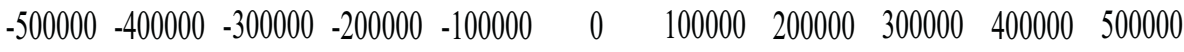

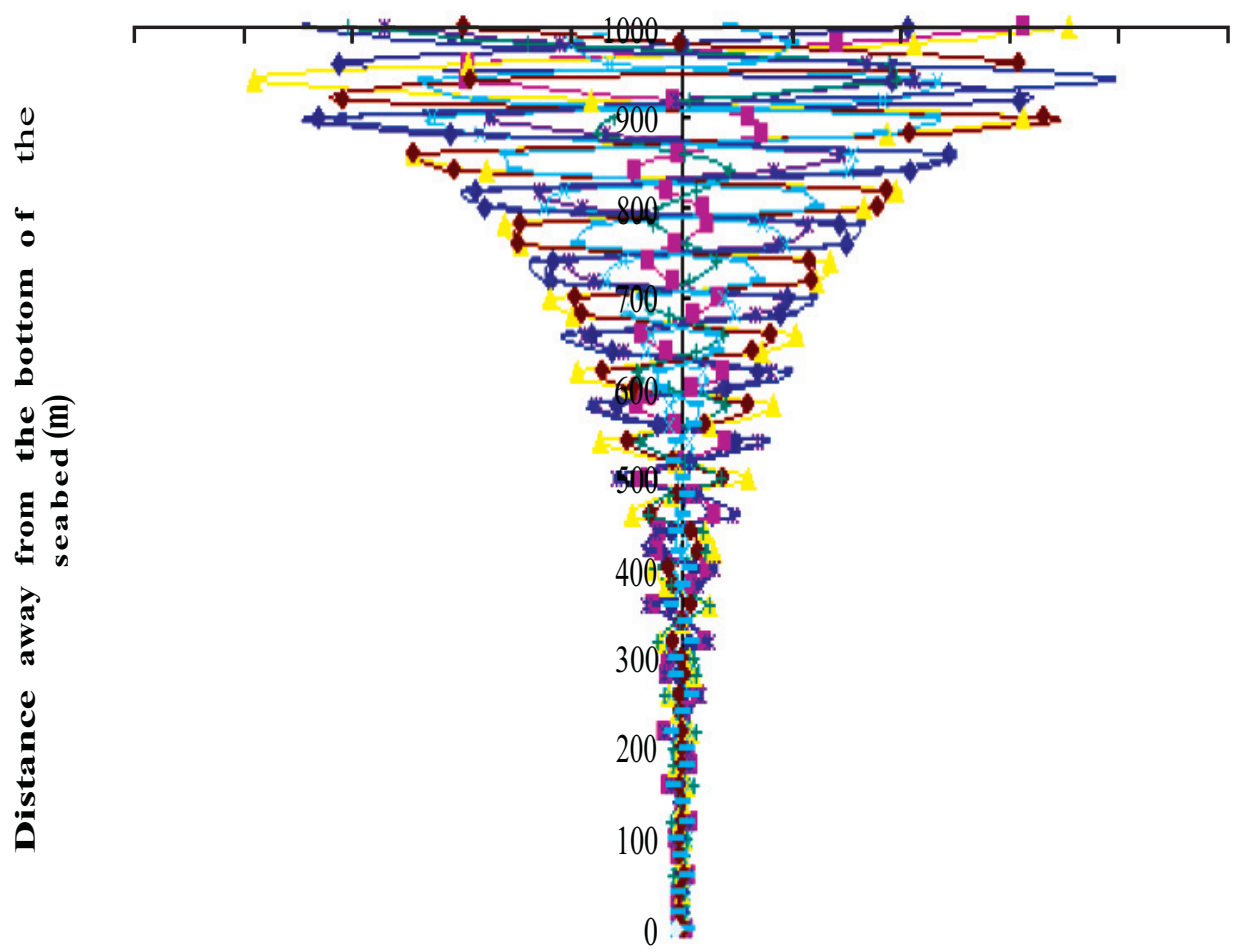

Fig (5). Shear force of the riser.

Transverse displacement of the riser (m)

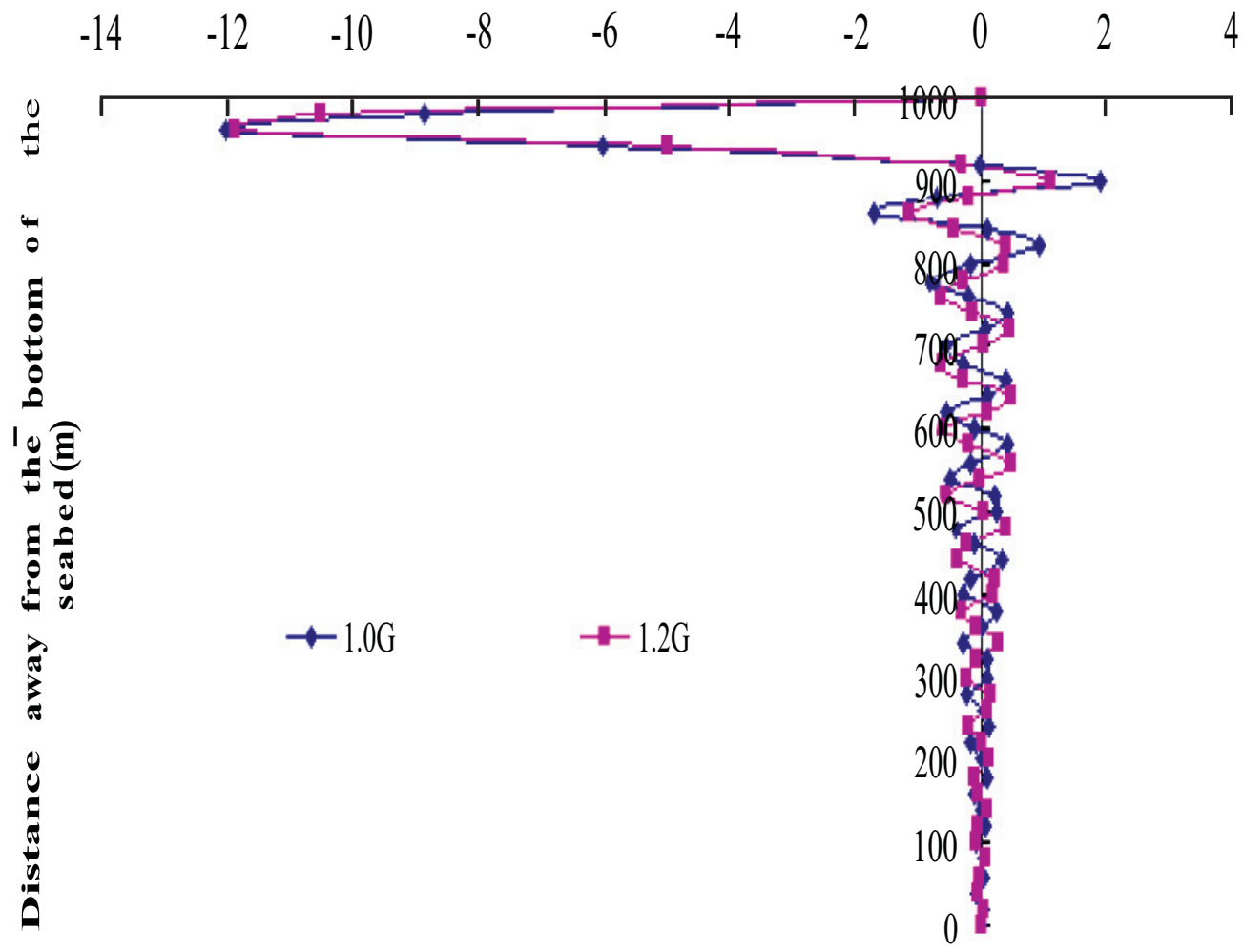

Fig (6). Transverse vibration of the riser under different tension. 
Transverse displacement of the riser $(\mathrm{m})$

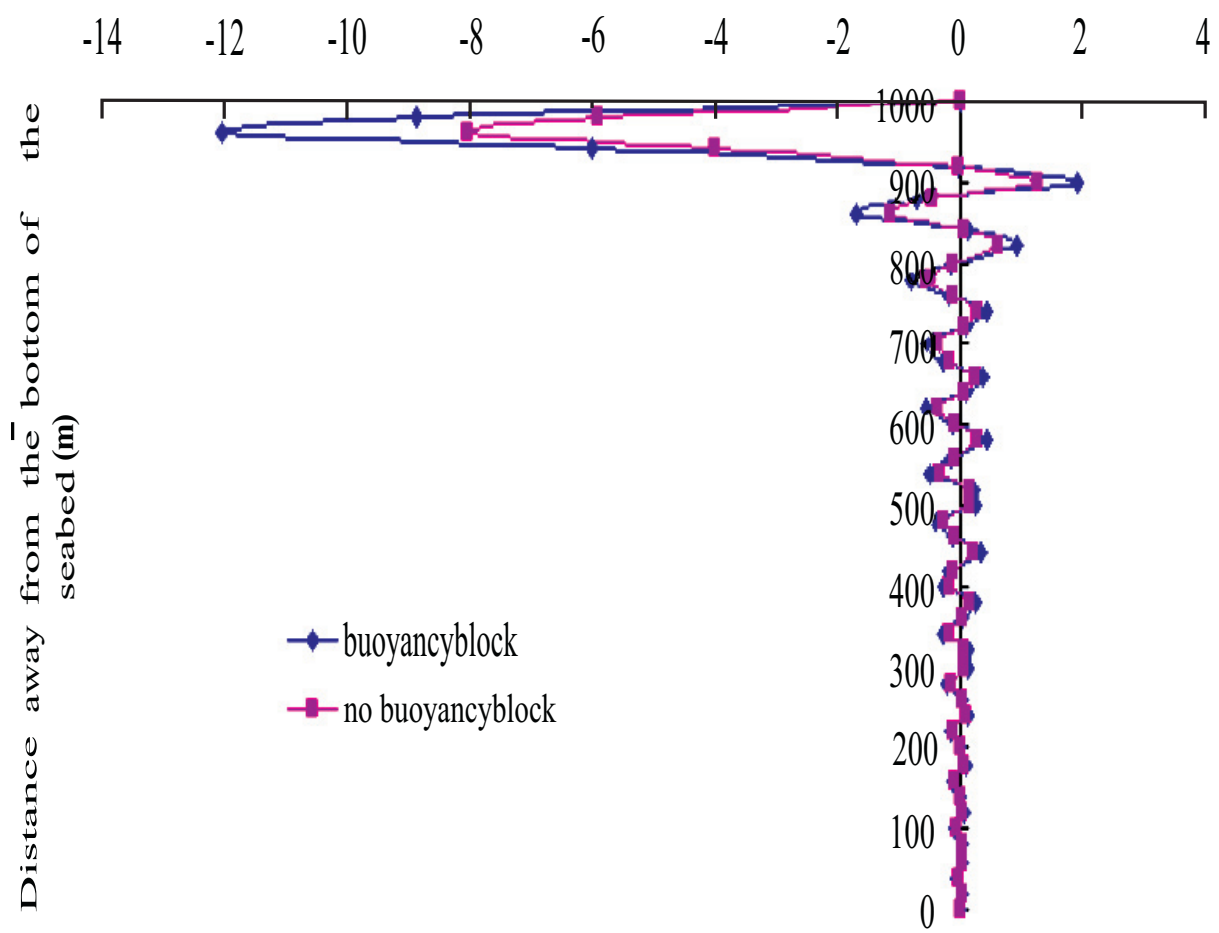

Fig. (7). Transverse vibration of the riser under the influence of the buoyancy.

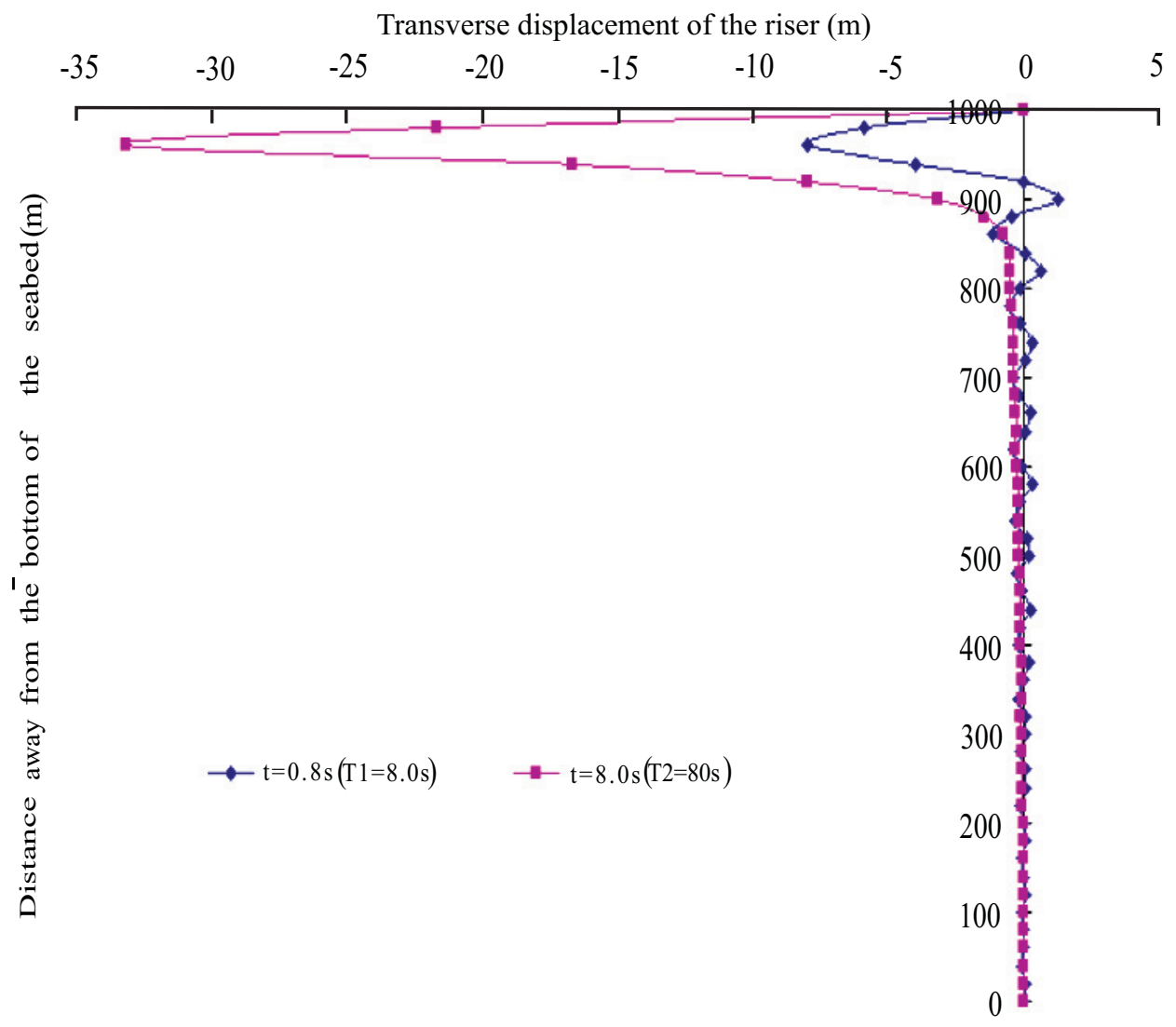

Fig. (8). Transverse vibration of the riser under different cycles. 


\section{CONCLUSION}

(1) Applying finite difference method to solve the riser transverse vibration mathematical model, calculation results can meet the needs of the project by the appropriate control precision.

(2) The largest transverse displacement is in the upper section of the riser in deepwater.

(3) The maximum of the riser bend angle is at the top of riser. In deep water, to control strictly the size of the inclination is of important significance, such as the internal pipe security working and preventing string eccentric wear.

(4) Increasing the riser top tension can reduce the riser transverse displacement response.

(5) Increasing buoyancy can reduce top tension for the offshore platform, but it will increase the riser transverse displacement response.

(6) With the cycle of current wave increased, the riser transverse displacement response increases, and vibration tends to be stable.

\section{CONFLICT OF INTEREST}

The authors confirm that this article content has no conflict of interest.

\section{ACKNOWLEDGEMENTS}

The paper is supported by the NSFC No. 51244004 and 51374183.

\section{REFERENCES}

[1] H.C. Fang, Ocean Petroleum Drilling Equipment and Structure. Beijing: Petroleum Industry Press, 1990.

[2] W. Jiang, "Lateral vibration performance of drilling riser and its impact to drilling operation", China Offshore oil and gas, vol. 19, pp. 394-397, December 2007

[3] W. Jiang, "Study on vibration characteristic of deep-water drilling riser" China Offshore oil and gas, vol. 21, pp. 329-331, October 2009

[4] X.B. Shi, and P. Chen, "Analysis of three-dimensional load influence on the strength of ocean deep water drilling riser" Gas Industry, vol. 24, pp. 86-88, December 2004

[5] J. Guesnon, C. Gaillard, and F. U. Richard, "Deep water drilling riser design and relative technology", Oil \& Gas Science and Technology, vol. 57, pp. 39-57, January 2002
[6] M.B. Irani, V. J. Modi, and F. Welf, "Riser dynamics with internal flow and nutation damping", In: Proceedings $6^{\text {th }}$ International Offshore Mechanic and Arctic Engineering Conference, 1987, vol 3, pp. 119-125.

[7] Y. H. Chen, and F.M. Lin, "General drag-force linearization fornonlinear analysis of marine risers", Ocean Engineering, vol 16, No 3, pp. 265-280, 1989.

[8] S. Kaewunruen, J. Chirawatcharadej, and S. Chucheepsakul, "Nonlinear free vibrations of marine risers/pipes transporting fluid", Ocean Engineering, vol 32, No 1-2, pp.417-440, 2005.

[9] K. Huang, and H. Chen, "Ultra deepwater riser interference analysis by using a time domain simulation approach with VIV effect", In: Proceedings D.O.T XVIII Conference, Houston, 2006.

[10] Guo HY, Fu Q, and Lou M, "Vortex-induced vibrations and fatigue life of marine risers conveying flowing fluid", Engineering Mechanics, vol. 22, pp. 220-224, August 2005.

[11] Li Z, Yang J, and Cao SJ, "Analysis of drilling riser mechanical behavior in deepwater", Oil Drilling and Production Technology, vol. 29, pp. 19-21, Februray 2007.

[12] K. Huang, H. Chen, and C. Chen,"Riser VIV-Induced Fatigue Assessment by a CFD Approach", In: Proceedings $18^{\text {th }}$ International Offshore and Polar Engineering Conference, Vancouver, ISOPE, 2008, vol 3, pp. 408-415.

[13] W. Qiu, J. S. Junior, D. Lee, H. Lie, V. Magarovskii, T. Mikami, JM. Rousset, S. Sphaier, L. Tao, and X. Wang, "Uncertainties related to predictions of loads and responses for ocean and offshore structures", Ocean Engineering, vol. 86, pp. 58-67, August 2014.

[14] S. Hirdaris, "Special issue on uncertainty modelling for ships and offshore sructures", Ocean Engineering, vol. 86, pp. 1-2, August 2014

[15] S.E. Hirdaris, W. Bai, D. Dessi, A. Ergin, X. Gu, O.A. Hermundstad, R. Huijsmans, K. Iijima, U.D. Nielsen, J. Parunov, N. Fonseca, A. Papanikolaou, K. Argyriadis, and A. Incecik, "Loads for use in the design of ships and offshore structures", Ocean Engineering, vol. 78, pp. 131-174, March 2014

[16] H. X. Wang, G. H. Zhao, and J. Zhang, "Discussion of transverse vibration model of riser under loads of internal flowing mud and external environmental", Oil Field Equipment, vol. 39, pp. 12-15, August 2010

[17] Y. R. Zhu, Wave Mechanics of Ocean Engineering, Tianjin University Press, 1991.

[18] V. Vengatesan, K. S. Varani, and N. Barltrop, "An experimental investigation of hydrodynamic coefficients for a vertical truncated rectangular cylinder due to regular and random waves" Ocean Engineering, vol. 27, pp. 291-313, June 2000.

[19] Y. C. Su, Partial Numerical Solution of Differential Equation, Beijing: Meteorological Press, 1989

[20] J. F. Fang, L. Z. Gu, and J. L. Chen, Partial Differential Equations Difference Method. Beijing: Higher Education Press, 1988.

[21] T. Wang, X. Z. Zhang, and W. Q. Zhu, "Study on nonlinear dynamic response of deep-water drilling riser with vessel motions", The Ocean Engineering, vol. 26, pp. 21-26, June 2008.

[22] T. Wang, X. Z. Zhang, and W. Q. Zhu, "Vessel motion effects on nonlinear dynamics of deep-water drilling riser", Journal of Ship Mechanics, vol. 14, pp. 606-617, December 2010.

(C) Li et al.; Licensee Bentham Open.

This is an open access article licensed under the terms of the Creative Commons Attribution Non-Commercial License (http://creativecommons.org/licenses/by-nc/3.0/) which permits unrestricted, non-commercial use, distribution and reproduction in any medium, provided the work is properly cited. 